\title{
Revisão do gênero Gounellea Lane (Coleoptera, Cerambycidae, Lamiinae, Anisocerini)
}

\section{Carlos Eduardo de Alvarenga Julio ${ }^{1}$}

\begin{abstract}
Revision of the genus Gounellea Lane (Coleoptera, Cerambycidae, Lamiinae, Anisocerini). The genus Gounellea Lane, 1964 is revised and new synonyms proposed, G. zikani $($ Melzer, 1932) $=$ G. melzeri $($ Franz, 1935) $=$ G. franzae Lane, $1970=$ G. bruchi (Gounelle, 1906). The species of Gounellea are keyed, redescribed and illustrated.

KEY WORDS. Cerambycidae, Anisocerini, Gounellea, revision, synonym
\end{abstract}

GOUNELLE (1906: 17) ao descrever Gymnocerus bruchi, procedente da Argentina, e Gymnocerus histrio, do Amazonas (Brasil), assinalou que estas duas espécies além de G. capucinum (White, 1846) e G. dulcissimum (White, 1855) reúnem caracteres, como padrão de coloração, espessamento apical no antenômero III e ausência de tubérculos na base dos élitros, que não se encontram nas demais espécies do gênero. Concluiu, por fim, que "ces quatres espèces qui s'écartent un peu de la formule du genre Gymnocerus, doivent former une section particulière". LANE (1964: 195) estabeleceu o gênero Gounellea para Compsosoma capucinum White, 1846 e LANE (1970: 378), referindo-se ao comentário de GounELLE (1906) e às espécies descritas por MELZER (1932) - G. zikani - e por FRANZ (1935) - G. melzeri - transferiu G. bruchi, G. dulcissimum, G. histrio, G. melzeri e G. zikani para Gounellea e descreveu G. franzae de Rondônia (Brasil).

Objetiva-se propor a sinonímia entre Gounellea franzae, G. melzeri, G. zikani e G. bruchi, redescrever o gênero e suas espécies e apresentar chave para identificação das espécies. Foram examinados exemplares pertencentes às coleções do Museu Nacional/Universidade Federal do Rio de Janeiro (MNRJ), Museu de Zoologia/Universidade de São Paulo (MZSP) e Departamento de Zoologia/Universidade Federal do Paraná (DZUP) e diapositivos dos holótipos de G. capucinum e G. dulcissimum feitos pelo Dr. J.S. Moure (DZUP) no The Natural History Museum, Londres.

\section{Gounellea Lane, 1964}

Gounellea Lane, 1964: 195; 1970: 378; Monné, 1994: 8 (cat.).

Espécie-tipo: Compsosoma capucinum White, 1846 (monotipia e designação original).

Fronte plana, granulada, com os lados paralelos e borda inferior com pequeno entalhe central nos machos e sub-reta nas fêmeas. Olhos grandes, não-divididos; lobos oculares superiores tão distantes entre si quanto o dobro da maior largura de um lobo. Tubérculos anteníferos afastados entre si, um pouco mais projetados nos

1) Departamento de Entomologia, Museu Nacional, Universidade Federal do Rio Janeiro. Quinta da Boa Vista, São Cristóvão, 20940-040 Rio de Janeiro, Rio de Janeiro, Brasil. E-mail: ceajulio@ig.com.br 
machos. Antenas, longas, ultrapassam os ápices elitrais tanto nos machos como nas fêmeas; escapo clavado, mais robusto nos machos; antenômero III, o mais longo, intumescido no lado interno do ápice; antenômero XI, nos machos, um pouco menor ou subigual ao $\mathrm{X}$ em comprimento e, nas fêmeas, com, aproximadamente, metade do comprimento do $\mathrm{X}$.

Protórax com tubérculo lateral cônico, proeminente; pronoto com as bordas anterior e posterior finamente pontuadas, a anterior reta e a posterior bissinuosa, e dois pequenos grânulos látero-anteriores manifestos. Mesosterno ligeiramente escavado no centro. Élitros convexos, estreitados atrás dos úmeros, alargados no meio e arredondados nos ápices; úmeros um pouco projetados, não-granulados; disco sub-liso, sem esculturas, granulados na margem basal, próximo ao escutelo, e na região centro-basal. Fêmures pedunculados, mais robusto nos machos; tíbias subretas, com uma linha dorsal de pubescência branca, as mesotíbias com escavação no terço apical; protarsos franjados nos machos.

Urosternito $\mathrm{V}$ das fêmeas com o mesmo comprimento dos três anteriores reunidos, truncado e ligeiramente escavado no ápice e com pequeno sulco central.

Comentários. Distingue-se de Gymnocerus, proposto por AUDINET-SERVILLE (1835), pelo antenômero III intumescido no lado interno do ápice; pelo antenômero $\mathrm{XI}$, nos machos, um pouco menor ou subigual ao $\mathrm{X}$ em comprimento e pelo formato e aspecto dos élitros, convexos, estreitados atrás dos úmeros, alargados no meio e arredondados nos ápices, com o disco sub-liso, sem esculturas, granulados na margem basal próximo ao escutelo e na região centro-basal e os úmeros não-granulados. Em Gymnocerus o antenômero III não possui intumescência apical; o antenômero XI é mais longo que o precedente e os élitros são subparalelos nos $2 / 3$ basais e gradualmente estreitados e arredondados no terço apical, com o disco densamente granulado na metade basal, com uma elevação longitudinal centro-basal e carenas longitudinais curtas, a interna mais saliente, na metade apical.

\section{Chave para as espécies de Gounellea}

1. Fronte com uma faixa transversal de pubescência laranja revestindo a borda inferior; região entre os lobos oculares superiores com uma faixa longitudinal de pubescência laranja que alcança a borda superior do pronoto; intumescimento do antenômero III discreto; antenômero XI, nos machos, subigual ao $\mathrm{X}$ em comprimento; região centro-basal dos élitros esparsamente granulada; escutelo esbranquiçado. Argentina, Bolívia, Peru e Brasil (Amazonas, Rondônia e Mato Grosso) (Fig. 2) ...................... G. bruchi

1'. Borda inferior da fronte e região entre os lobos oculares superiores negras, sem faixa de pubescência laranja; intumescimento do antenômero III desenvolvido; antenômero XI menor que o X; região centro-basal dos élitros densamente granulada; escutelo negro ou laranja . . . . . . . . . . . . 2

2. Escutelo laranja; metade apical dos élitros com quatro máculas negras, arredondadas, desiguais em tamanho; metade basal com uma faixa transversal larga, laranja ou negra, com as bordas superior e inferior sub-retas. Brasil (Pará e Mato Grosso) (Fig. 3) ........................... G. dulcissima 
2'. Escutelo negro; metade apical dos élitros com uma faixa oblíqua de bordas retas ou uma série de máculas unidas irregulares; e uma mácula negra próxima ao ápice, arredondada ou triangular; metade basal com uma faixa transversal negra de bordas superior e inferior irregulares ou com uma faixa negra com a borda superior reta transversal e a inferior curva oblíqua ........... 3

3. Antenômero XI com a metade do comprimento do X; élitros, com exceção das faixas negras, predominantemente alaranjados; metade apical dos élitros com uma série de máculas unidas irregulares e uma mácula arredondada próxima ao ápice; metade basal com uma faixa transversal de bordas irregulares. Brasil (Amazonas, Pará, Maranhão, Rondônia e Mato Grosso) (Fig. 1)

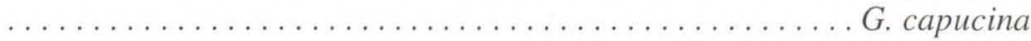

3'. Antenômero XI com 2/3 do comprimento do X; élitros, com exceção das faixas negras, predominantemente amarelados; metade apical dos élitros com uma faixa oblíqua de bordas retas e uma mácula triangular próxima ao ápice; metade basal com uma faixa de borda superior reta transversal e inferior curva oblíqua. Peru e Brasil (Amazonas e Pará) (Fig. 4) ........ G. histrio

\section{Gounellea capucina (White, 1846)}

Fig. 1

Compsosoma capucinum White, 1846: 48, est. 1, fig. 7.

Anisocerus capucinus; White, 1855: 406.

Gymnocerus capucinus; Bates, 1862: 452; Lacordaire, 1872: 722; Schulz, 1901: 335 (distr.); Gounelle, 1906: 17.

Gounellea capucinum; Lane, 1964: 195; 1970: 378; Monné, 1994: 8 (cat.).

Macho. Tegumento negro. Fronte densamente granulada, com a borda inferior sub-reta, o entalhe central bastante discreto. Genas e região abaixo dos lobos oculares inferiores com uma faixa de pubescência laranja. Tubérculos anteníferos um pouco projetados. Antenas ultrapassam os ápices elitrais com três antenômeros; escapo clavado com aproximadamente $2 / 3$ do comprimento do antenômero III, este o mais longo e com intumescimento desenvolvido no lado interno do ápice; antenômeros IV-X gradualmente decrescentes em comprimento; o XI com metade do comprimento do $\mathrm{X}$.

Protórax com tubérculos laterais cônicos; pronoto sub-liso, os grânulos láteroanteriores bastante discretos. Escutelo negro. Élitros parcialmente revestidos por pubescência alaranjada; a região centro-basal densamente granulada e com pontuação esparsa; margem basal, próxima ao escutelo, borda anterior dos úmeros e metade apical das margens suturais negras; metade basal com uma faixa transversal negra, de bordas irregulares; metade apical com uma série de máculas negras unidas e irregulares e uma mácula negra e arredondada próxima ao ápice; epipleuras laranjas.

Fêmea. Borda inferior da fronte reta; antenas ultrapassam os ápices elitrais com apenas dois antenômeros.

Dimensões (em milímetros) respectivamente macho e fêmea. Comprimento total, 12,5 e 11,3-13,0; comprimento do protórax, 2,6 e 2,1-2,5; maior largura do protórax, 5,4 e 5,0-5,5; comprimento do élitro, 9,0 e 8,2-9,1; largura umeral, 6,5 e $5,7-6,6$. 
Material examinado. BraSIL, Amazonas: São Paulo de Olivença, fêmea, F. Tippmann leg. Pará: Paragominas (Itiuga), fêmea, I/1965, L. Gomes leg.; Utinga, macho, XII/1960, Bechyné leg. (MZSP). Maranhão: Imperatriz (Horto Florestal Arara Azul), macho, X/2001, L. F. Reys leg. (MNRJ).

Comentários. Gounellea capucina foi mencionada por MonNÉ (1994: 8) para Rondônia e Mato Grosso.

Assemelha-se a $G$. histrio pela borda inferior da fronte e região entre os lobos oculares superiores negras, sem a presença da faixa de pubescência laranja; pelo intumescimento do antenômero III desenvolvido e pelo escutelo negro. Distingue-se de $G$. histrio pelo antenômero XI com metade do comprimento do X; pelos élitros, com exceção das faixas negras, predominantemente alaranjados; pela metade apical dos élitros com uma série de máculas unidas e irregulares e uma mácula arredondada próxima ao ápice e pela metade basal com uma faixa transversal de bordas irregulares. Em G. histrio: antenômero XI com 2/3 do comprimento do X; élitros, com exceção das faixas negras, predominantemente amarelados; metade apical dos élitros com uma faixa oblíqua de bordas retas e uma mácula triangular próxima ao ápice e a metade basal com uma faixa de borda superior reta transversal e inferior curva oblíqua.

\section{Gounellea bruchi (Gounelle, 1906)}

Fig. 2

Gymnocerus bruchi Gounelle, 1906: 17, fig. 1; Bruch, 1912: 212 (cat.).

Gounellea bruchi; Lane, 1970: 378; Monné, 1994: 8 (cat.).

Gymnocerus zikani Melzer, 1932: 220, est. 3, fig. 1; Zikán \& Wygodzinsky, 1948: 53 (tipo). Syn. nov. Gounellea zikani; Lane, 1970: 378; Monné, 1994: 9 (cat.).

Gymnocerus melzeri Franz, 1935: 169, fig. 1. Syn. nov.

Gounellea melzeri; Lane, 1970: 378; Monné, 1994: 9 (cat.).

Gounellea franzae Lane, 1970: 378; Monné, 1994: 9 (cat.). Syn. nov.

Macho. Tegumento negro. A borda inferior da fronte, as genas, embaixo dos lobos oculares inferiores, e a região entre os lobos oculares superiores, revestidos por uma faixa laranja.

Fronte com granulação discreta, a borda inferior com pequeno entalhe central; tubérculos anteníferos ligeiramente projetados. Antenas, longas, ultrapassam o ápice elitral a partir do antenômero VI; escapo moderadamente clavado, finamente pontuado, com $2 / 3$ do comprimento do antenômero III, aproximadamente, e este subigual ao IV, com intumescimento discreto do lado interno do ápice; antenômeros V-XI gradualmente decrescentes em comprimento; XI subigual ao X.

Tubérculos laterais do protórax proeminentes, cônicos e afilados no topo. Pronoto com dois pequenos grânulos látero-anteriores. Escutelo branco. Élitros revestidos, na base, por uma estreita faixa de pubescência amarela e, abaixo desta, uma faixa transversal negra, larga, esparsamente pontuada e de contornos retos, indo de uma margem a outra; margem basal, próxima ao escutelo, negra e granulada; borda anterior dos úmeros negra; epipleura com os $2 / 3$ basais laranja; região centro-basal com uma pequena elevação granulada; metade apical revestida por 

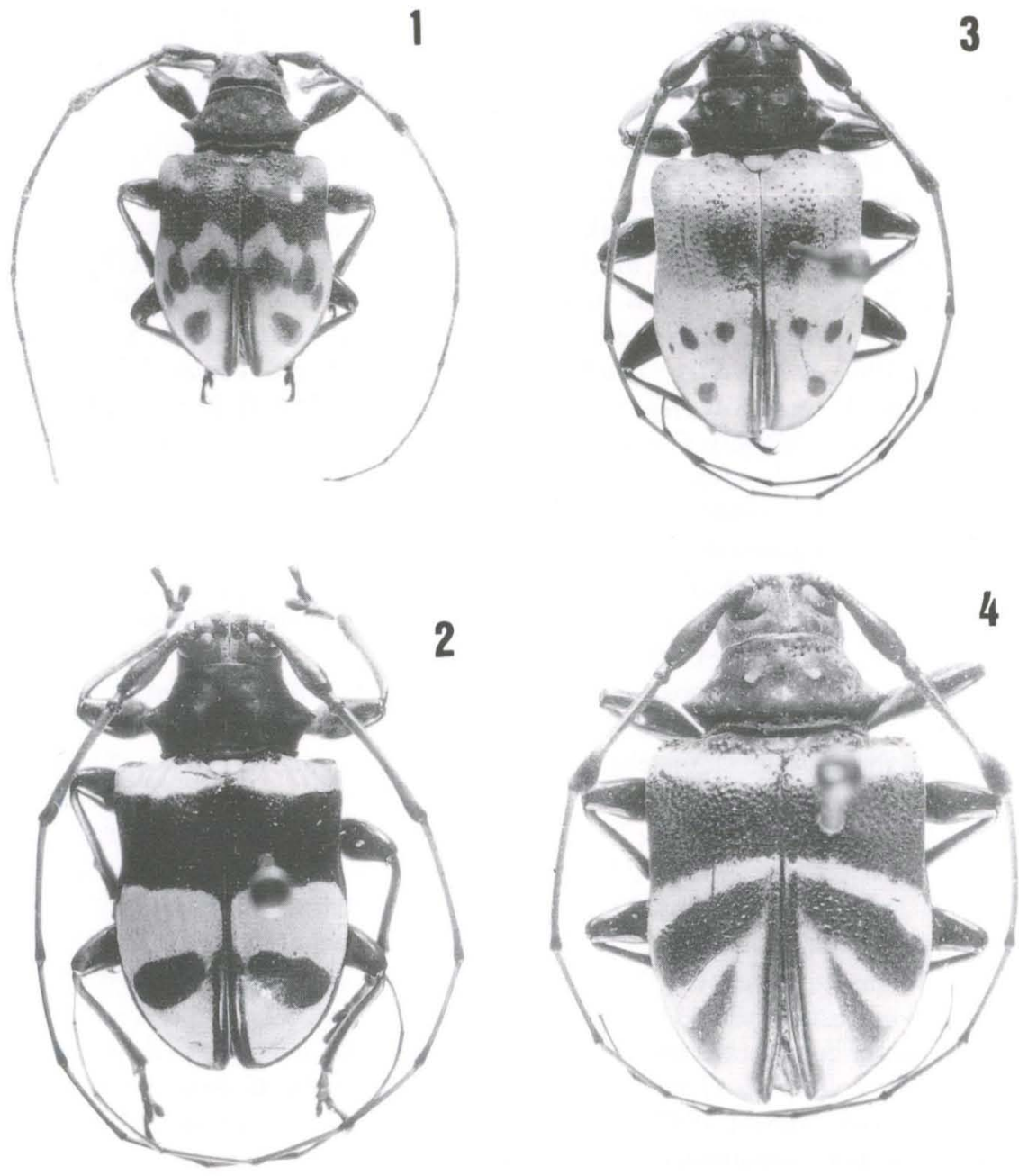

Figs 1-4. (1) Gounellea capucina macho (MZSP), Utinga, Pará, Brasil, comprimento 12,5 mm; (2) Gounellea bruchi macho (MNRJ), Barra do Bugres, Mato Grosso, Brasil, comprimento 13,0 mm; (3) Gounellea dulcissima macho (MNRJ), Itaituba, Pará, Brasil, comprimento 13,0 mm; (4) Gounellea histrio macho (MNRJ), Borba, Amazonas, Brasil, comprimento 14,1 mm.

pubescência esbranquiçada, com uma faixa oblíqua negra que não atinge as margens lateral e sutural; margens suturais com os 2/3 apicais negros. Tarsos revestidos por pubescência decumbente branca.

Fêmea. Borda inferior da fronte sub-reta; antenas ultrapassam o ápice elitral a partir do antenômero VIII; urosternito V escavado no ápice e com pequeno sulco central. 
Dimensões (em milímetros) respectivamente macho e fêmea. Comprimento total, 9,3-15,8 e 10,6-15,8; comprimento do protórax, 1,8-3,5 e 2,0-3,1; maior largura do protórax, 3,6-7,0 e 4,1-6,2; comprimento do élitro, 6,4-12,0 e 7,3-11,6; largura umeral, 4,4-8,6 e 5,1-8,6.

Material examinado. BRASIL, Amazonas: Humaitá, macho, VIII/1980, G.S. Andrade leg. (MNRJ); macho, IX/1980, B. Silva leg. (MNRJ). Pará: Manicore (Rio Madeira), macho, IX/1941, A. Parko leg. (MNRJ). Rondônia: Ariquemes, macho, XI/1979, B. Silva leg. (MNRJ); macho e fêmea, XI/1991, Mielke leg. (DZUP); Forte Príncipe, 3 machos e 2 fêmeas (todos parátipos de G. franzae), XI/1961, F.M. Oliveira leg. (MNRJ); Ouro Preto do Oeste, 3 fêmeas, VIII/1980, B. Silva leg.; fêmea, X/1980, B. Silva leg.; macho, X/1980, 5 machos e 8 fêmeas, X/1983, O. Roppa, J. Becker \& B. Silva leg.; 6 machos e 4 fêmeas, X/1986, O. Roppa, P. Magno \& J. Becker leg. (MNRJ); fêmea, XI/1987, C. Elias leg. (DZUP); Pimenta Bueno, macho, XI/1960, M. Alvarenga leg.; macho, X/1986, O. Roppa, P. Magno \& J. Becker leg. (ambos MNRJ); Porto Velho, macho, IX/1978; 3 machos, X/1978, J. Becker leg.; (Cachoeira do Samuel), 3 machos e 2 fêmeas (holótipo e parátipos de G. franzae), XI/1944, A. Parko leg.; (Guaporé), fêmea (parátipo de G. franzae), XI/1954, F. Pereira, Werner, Dante \& M. Alvarenga leg. (MNRJ); Vilhena, 2 fêmeas (parátipos de G. franzae), XI/1960, M. Alvarenga leg.; 2 machos e 2 fêmeas, XI/1973, Alvarenga \& Roppa leg.; macho e 2 fêmeas, X/1988, O. Roppa, P. Magno \& J. Becker leg.; 2 fêmeas, X/1990, O. Roppa \& J. Becker leg. (MNRJ). Mato Grosso: Barra do Bugres, 2 machos, X/1984, B. Silva leg.; macho e fêmea, XI/1984, O. Roppa \& B. Silva leg.; Diamantino, macho, XI/1971, S. A. Fragoso leg.; 6 machos, X/1983, B. Silva leg.; Nobres, macho e 2 fêmeas, III/1977, Milton leg.; Sinop, macho e 2 fêmeas, IX/1974, 3 machos e 5 fêmeas, X/1974, 6 machos e fêmea, X/1975, 3 machos e 2 fêmeas, X/1976, 2 machos e 3 fêmeas, XI/1976, Alvarenga \& Roppaleg.; Vera, 3 machos e 4 fêmeas, X/1973, Alvarenga \& Roppa leg. (MNRJ).

Discussão. FranZ (1935: 169) ao descrever G. melzeri, procedente do Peru, assinalou que esta espécie é próxima de G. zikani Melzer, 1932 e, possivelmente, só deveria ser considerada uma subespécie. O exame dos exemplares disponíveis, inclusive do holótipo de G. franzae Lane, 1970, das figuras de G. bruchi (Gounelle, 1906), G. zikani (Melzer, 1932) e G. melzeri (Franz, 1935) e das descrições originais, permitiu propor a sinonímia entre essas espécies.

Além das localidades mencionadas, MonNÉ (1994: 9) citou G. franzae para a Bolívia.

Como variações cromáticas, $G$. bruchi apresenta a metade apical dos élitros revestida por pubescência amarelada, com a faixa oblíqua negra atingindo as margens sutural e lateral, uma mácula arredondada negra próxima ao ápice e a região entre os lobos oculares superiores negra, não revestida pela faixa longitudinal laranja.

Distingue-se das demais espécies do gênero pela borda inferior da fronte revestida por uma faixa transversal laranja; pelo intumescimento do antenômero III discreto; pelo antenômero XI, nos machos, subigual ao X em comprimento e pelo escutelo esbranquiçado. Nas demais espécies a borda inferior da fronte é negra; o antenômero III possui uma intumescência desenvolvida no lado interno do ápice; o antenômero XI é menor que o X em comprimento e o escutelo é negro ou laranja. 


\section{Gounellea dulcissima (White, 1855)}

Fig. 3

Anisocerus dulcissimus White, 1855: 406.

Gymnocerus dulcissimus; Bates, 1862: 452; Lacordaire, 1872: 722; Gounelle, 1906: 17; Melzer, 1932: 221 (distr.).

Gounellea dulcissimus; Lane, 1970: 378.

Gounellea dulcissimum; Monné, 1994: 9 (cat.).

Macho. Tegumento negro. Fronte densamente granulada, a borda inferior com pequeno entalhe central. Genas e região abaixo dos lobos oculares inferiores com uma faixa de pubescência laranja. Tubérculos anteníferos um pouco projetados. Antenas ultrapassam os ápices elitrais a partir do antenômero VI; escapo clavado, com, aproximadamente, a metade do comprimento do antenômero III; este subigual ao do IV e com intumescimento desenvolvido no lado interno do ápice; antenômeros V-XI gradualmente decrescentes em comprimento; o XI com 2/3 do comprimento do X.

Protórax com tubérculos laterais cônicos e proeminentes; pronoto com dois pequenos grânulos látero-anteriores manifestos. Escutelo laranja. Élitros parcialmente revestidos por pubescência amarela, numa estreita faixa abaixo do escutelo e na metade apical; metade basal com duas faixas transversais de pubescência laranja, uma estreita na borda anterior e outra mais larga e mediana, esta com as bordas superior e inferior sub-retas; região centro-basal densamente granulada e com pontuação esparsa; metade apical com quatro máculas negras, arredondadas e desiguais em tamanho; todo o contorno elitral, inclusive os úmeros, revestido por pubescência laranja; margens suturais com a metade apical negra; epipleuras laranjas.

Fêmea. Borda inferior da fronte sub-reta; antenas com, aproximadamente, o mesmo comprimento do corpo, ultrapassando-o com apenas um antenômero.

Dimensões (em milímetros) respectivamente macho e fêmea. Comprimento total, 10,6-13,0 e 11,7; comprimento do protórax, 1,9-2,4 e 2,1; maior largura do protórax, 4,0-5,1 e 4,7; comprimento do élitro, 7,5-9,1 e 8,6; largura umeral, 4,8-6,5 e 5,7 .

Material examinado. BRASIL, Pará: Altamira, macho, XII/1962, Diringshofen leg. (MZSP); Itaituba (Rio Tapajós), fêmea, XII/1962; macho, X/1963; macho, X/1964 (MNRJ). Mato Grosso: Xingu, macho, XI/1955, Inácio leg. (MNRJ).

Comentários. Gounellea dulcissima apresenta, como variações cromáticas, os élitros parcialmente revestidos por pubescência amarelo-clara, na estreita faixa abaixo do escutelo e na metade apical, sendo a larga faixa basal negra.

Assemelha-se a G. capucina e G. histrio pela borda inferior da fronte e região entre os lobos oculares superiores negras, sem faixa de pubescência laranja; pelo intumescimento do antenômero III desenvolvido; pelo antenômero XI menor que o $\mathrm{X}$ e pela região centro-basal dos élitros densamente granulada. Distingue-se de $G$. capucina e $G$. histrio pelo escutelo laranja e pelo aspecto dos élitros, com a metade apical com quatro máculas negras arredondadas, desiguais em tamanho, e a metade basal com uma faixa transversal larga de bordas superior e inferior sub-retas. Em $G$. capucina e $G$. histrio o escutelo é negro e os élitros apresentam na metade apical uma faixa oblíqua ou uma série de máculas unidas irregulares e uma mácula negra 
próxima ao ápice e na metade basal a larga faixa transversal tem um formato distinto, com as bordas superior e inferior irregulares ou a superior reta transversal e a inferior curva oblíqua.

\section{Gounellea histrio (Gounelle, 1906)}

Fig. 4

Gymnocerus histrio Gounelle, 1906: 18, fig. 2; Melzer, 1932: 221 (distr.); Soukup, 1942: 308 (distr.). Gounellea histrio; Lane, 1970: 378; Monné, 1994: 9 (cat.).

Macho. Tegumento negro. Fronte densamente granulada, a borda inferior com pequeno entalhe central. Genas e região abaixo dos lobos oculares inferiores com uma faixa de pubescência laranja. Tubérculos anteníferos pouco projetados. Antenas ultrapassam os ápices elitrais a partir do antenômero VI; escapo com, aproximadamente, $2 / 3$ do comprimento do antenômero III, este subigual ao IV e com intumescimento desenvolvido no lado interno do ápice; antenômeros V-XI gradualmente decrescentes em comprimento; o XI com $2 / 3$ do comprimento do X.

Tubérculos laterais do protórax cônicos, proeminentes e um pouco afilados no topo; pronoto com a superfície irregular e com dois grânulos látero-anteriores. Escutelo negro. Élitros parcialmente revestidos por pubescência amarelada; região centro-basal densamente granulada-pontuada; metade basal com uma faixa negra com a borda superior reta transversal e a inferior curva oblíqua; metade apical com uma faixa oblíqua de bordas retas e uma mácula triangular próxima ao ápice; a borda anterior dos úmeros e uma estreita área próxima ao escutelo negras; epipleuras com os $2 / 3$ basais amarelos; margens suturais com os $2 / 3$ apicais negros; ápices laranjas. Fêmures anteriores e médios mais robustos; tíbias com uma linha dorsal de pubescência branca, estendendo-se até os tarsômeros I e II.

Fêmea. Borda inferior da fronte reta; antenas ultrapassam os ápices elitrais com dois antenômeros.

Dimensões (em milímetros) respectivamente macho e fêmea. Comprimento total, 11,6-15,1 e 12,0-16,0; comprimento do protórax, 2,1-2,8 e 2,2-2,8; maior largura do protórax, 4,6-6,0 e 4,7-6,6; comprimento do élitro, 8,2-10,6 e 8,3-11,5; largura umeral, 5,6-7,0 e 5,7-8,5.

Material examinado. BRASIL, Amazonas: Borba (Lago Acará), macho e fêmea, VIII/1943, macho, XI/1943, A. Parko leg. Pará: Itaituba, fêmea, 1940; fêmea, XII/1963; Jacareacanga, macho, VIII/1969, macho, X/1970, F.R. Barbosa leg. (MNRJ).

Comentários. Além das localidades mencionadas acima, MONNÉ (1994: 9) registrou G. histrio para o Peru.

Assemelha-se a G. capucina pela borda inferior da fronte e região entre os lobos oculares superiores negras, sem a presença da faixa de pubescência laranja; pelo intumescimento do antenômero III desenvolvido e pelo escutelo negro. Distingue-se de G. capucina pelo antenômero XI com 2/3 do comprimento do X; pelos élitros, com exceção das faixas negras, predominantemente amarelados; pela metade apical dos élitros com uma faixa oblíqua de bordas retas e uma mácula triangular próxima ao ápice e a metade basal com uma faixa com a borda superior reta 
transversal e a inferior curva oblíqua. Em G. capucina: antenômero XI com metade do comprimento do X; élitros, com exceção das faixas negras, predominantemente alaranjados; metade apical dos élitros com uma série de máculas unidas irregulares e uma mácula arredondada próxima ao ápice e a metade basal com uma faixa transversal de bordas superior e inferior irregulares.

AGRADECIMENTOS. Ao Dr. Miguel A. Monné (MNRJ) pelas sugestões e revisão do manuscrito; ao Dr. Ubirajara R. Martins (MZSP) pelo empréstimo de material; ao Dr. Renato C. Marinoni (DZUP) pelo empréstimo de material e dos diapositivos; ao Prof. Johann Becker (MNRJ) pela tradução dos originais em alemão; a Sérgio Barbosa Gonçalves pela execução das fotografias e a Fundação de Amparo à Pesquisa do Estado de São Paulo (FAPESP, Proc. 98/10692-5) pela bolsa de Doutorado concedida (Instituto de Biociências, UNESP/Botucatu).

\section{REFERÊNCIAS BIBLIOGRÁFICAS}

Audinet-Serville, J.G. 1835. Nouvelle classification de la famille des longicornes. Annls Soc. Ent. France, Paris, 4 (1): 5-100.

BAtes, H.W. 1862. Contributions to an insect fauna of the Amazon Valley. Coleoptera. Longicornes. Ann. Mag. nat. Hist., London, 9 (3): 446-458.

Bruch, C. 1912. Catálogo sistemático de los Coleópteros de la República Argentina. Pars VIII. Família Cerambycidae. Revta Mus. La Plata 18: 179-226.

Franz, E. 1935. Neues zur Gattung Gymnocerus Serv. (Col.,Cerambycidae). Ent. Rdsch., Stuttgart, 52: 169-172.

Gounelle, E. 1906. Cérambycides nouveaux ou peu connus de la région néotropicale principalement de la sous-region brésilienne. Annls Soc. ent. France, Paris, 75: 1-20.

LaCordatre, J.T. 1872. Histoire Naturelle des Insectes. Genera des Coléoptères. Paris, Roret, 9 (2): 411-930.

Lane, F. 1964. Novos gêneros e espécies de Anisocerini (Coleoptera, Lamiidae). Studia Ent., Petrópolis, 7: $179-200$. $369-428$.

Melzer, J. 1932. Vinte espécies novas de cerambycideos neotrópicos, principalmente do Brasil. Rev. Ent., Rio de Janeiro, 2 (2): 216-238.

MonNÉ, M.A. 1994. Catalogue of the Cerambycidae (Coleoptera) of the Western Hemisphere. Part XVII. São Paulo, Sociedade Brasileira de Entomologia, 110p.

ScHULZ, W.A. 1901. Biologische, zoogeographische un synonymische Notizen aud der Käferfauna des unteren Amazonenstroms. Berl. ent. Ztschr. 46: 321-338.

SoukuP, J. 1942. Apuntes para la zoogeografia entomológica. Boln Mus. Hist. nat. Javier Prado, Lima, $6(22-23): 302-342$.

White, A. 1846. Descriptions of four apparently new species of longicorn beetles in the collection of the British Museum. Ann. Mag. nat. Hist., London, 18: 47-49.

- 1855. Catalogue of the coleopterous insects in the collection of the British Museum. Longicornia 2. London, 8: 175-412.

ZiKÁn, W. \& P. WygOdZINSKY. 1948. Catálogo dos tipos de insetos do Instituto de Ecologia e Experimentação Agrícolas. Bol. Serv. Pesq. Agron., Rio de Janeiro, 4: 1-93. 